$\mathrm{Oz}$

Volume 34

Article 7

$1-1-2012$

\title{
Hydroelectric Power Station
}

Michael Becker

Franz G. Schröck

Bernhard Kast

Follow this and additional works at: https://newprairiepress.org/oz

Part of the Architecture Commons

(c) (i) $\Theta(9$

This work is licensed under a Creative Commons Attribution-Noncommercial-No Derivative Works 4.0 License.

\section{Recommended Citation}

Becker, Michael; Schröck, Franz G.; and Kast, Bernhard (2012) "Hydroelectric Power Station," Oz: Vol. 34. https://doi.org/10.4148/2378-5853.1503

This Article is brought to you for free and open access by New Prairie Press. It has been accepted for inclusion in Oz by an authorized administrator of New Prairie Press. For more information, please contact cads@k-state.edu. 


\title{
Hydroelectric Power Station
}

\author{
Michael Becker, Franz G. Schröck, Bernhard Kast / Photographs by Brigida González \\ Becker Architekten
}

On the left bank of the Iller River, a new, highly efficient hydroelectric power station has been built to replace an older power station from the 1950s. The power station supports approximately three thousand households with 10.5 million kilowatt-hours of environmentally friendly power per year. Specialized engineering consultants had nearly finished planning the project when the authorizing agency demanded a design that would fit subtly into the historically registered block containing a former spinnery/ weavery while also blending in with the natural environment of the Iller.

The starting point for design considerations was the symbolic representation of the river's dynamics, ranging from a calm state at the water inlet to a churning and pitching state near the turbines before subsequently returning to a calm state after electricity generation. Further inspiration included the river-washed rock formations in close proximity to the location of the power plant. The design is intended to connect the the two ends of the machine room with a continuous concrete shell which pinches underneath the historical steel framework of a former bridge in order to avoid the bridge's demolition.

The organic shell cloaks the underground, technical engineering elements while the organic shape means each observer creates his or her own image for the building. Common metaphors include a smoothed river stone, a frozen wave, or a stranded whale

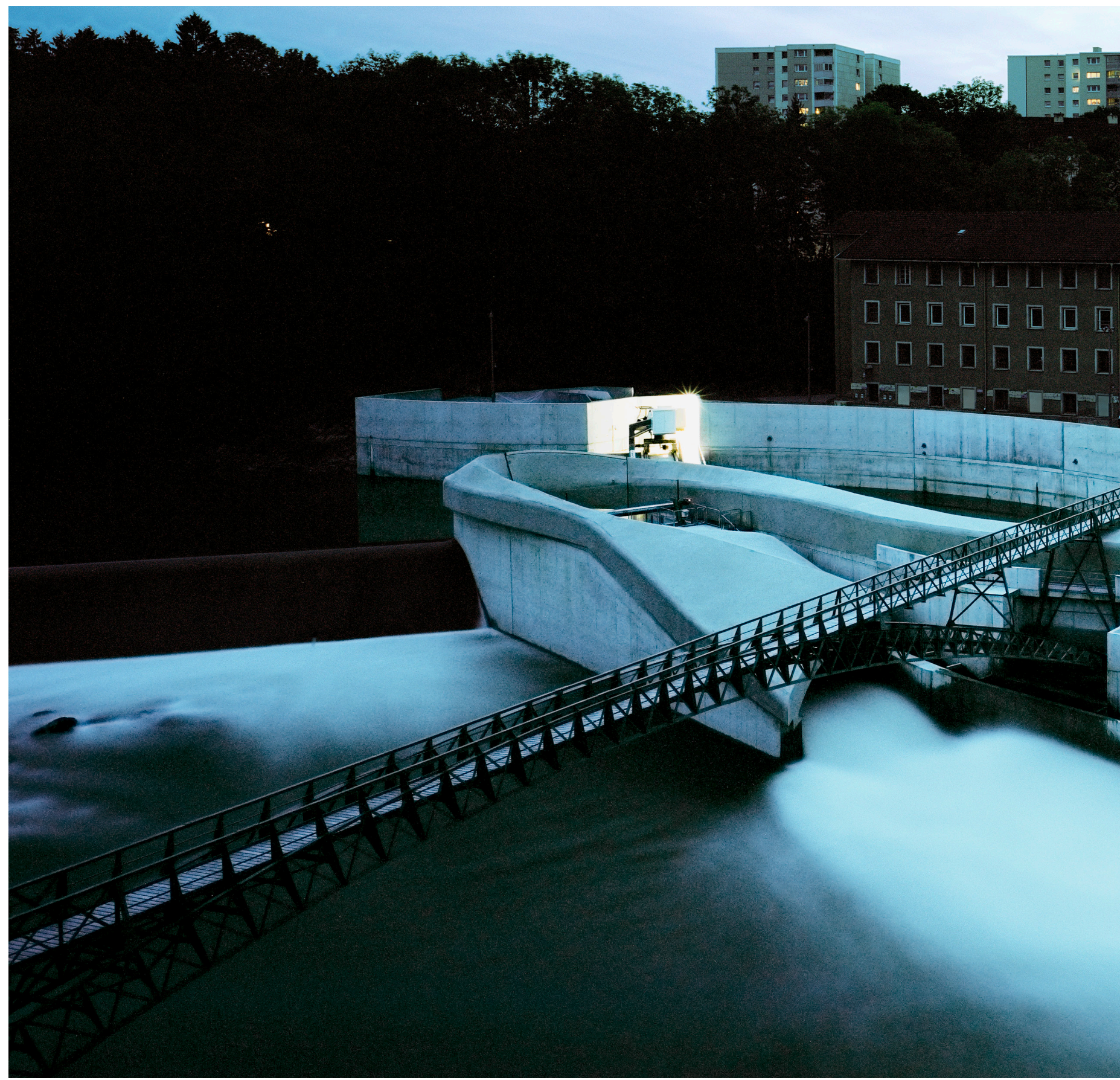



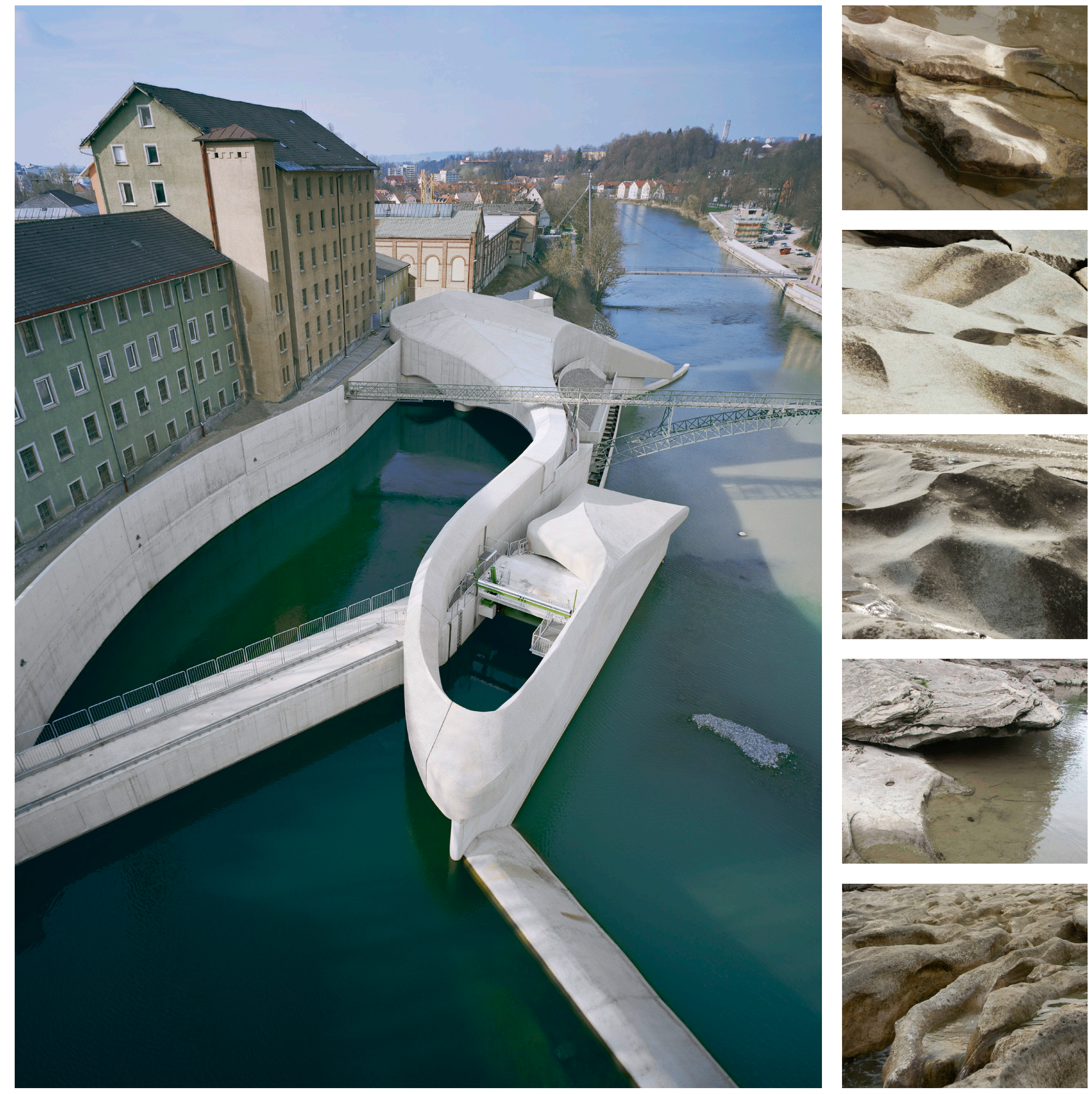


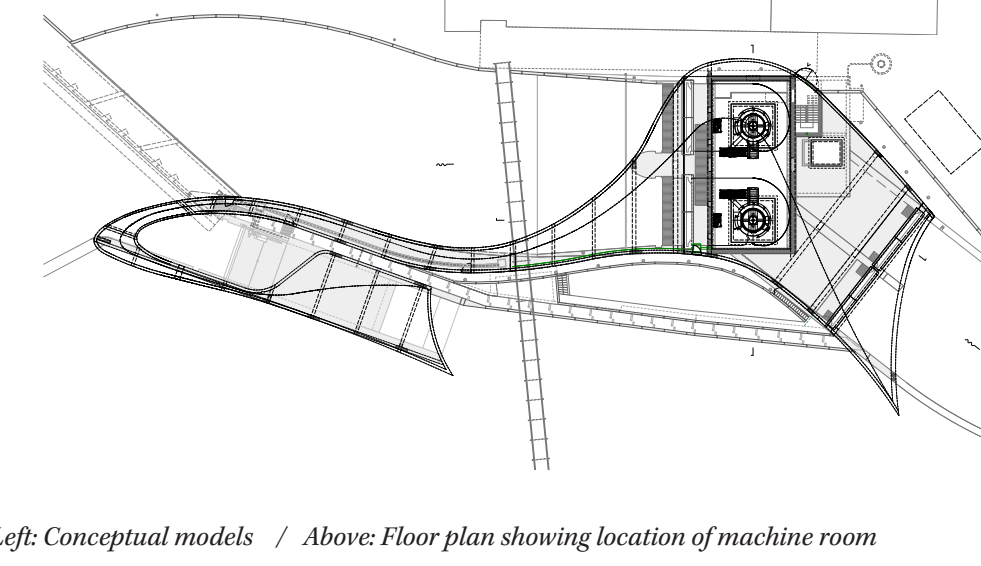

In continuity with the underground construction, the reinforced concrete wrapping is fitted on selective plate bearings with a revolving gap of $2 \mathrm{~cm}$ in order to compensate for longitudinal deformation. In the transverse direction, ribs, similar to the ribs in a boat, stabilize the construction while openings are minimized to preserve a monolithic and homogenous feeling. The skeletal structure generates a fascinating sequence of interior rooms, alternating between dome-like proportions and intimate sizes. The three-dimensional curved concrete interior was formed by a rough wooden plank formwork and is protected by a light coating of reflective gravel sealant on the exterior surfaces which transforms the structure's appearance according to changing weather and light. The interior lighting escapes through gaps and joints in the shells as well as the plant's inlet and outlet, subtly highlighting the structure.
Environmental and acoustic concerns were also taken into account in the design and development of the power station. Local fish ecologies were protected through the integration of a fish ladder to facilitate migration. In addition, the power plant's location required close attention to be paid to the reduction of airborne and structureborne noise.

Despite the huge dimensions, a multivalent structure was created: a structure which fades into its surroundings but also provides a sculptural and exciting addition to the waterfront, allowing the public to experience the process through which hydroelectricity is created through cyclist and pedestrian paths running through and over the structure. The project hopes to be the first of many interventions working in concert to beautify and functionalize the city's waterfront.
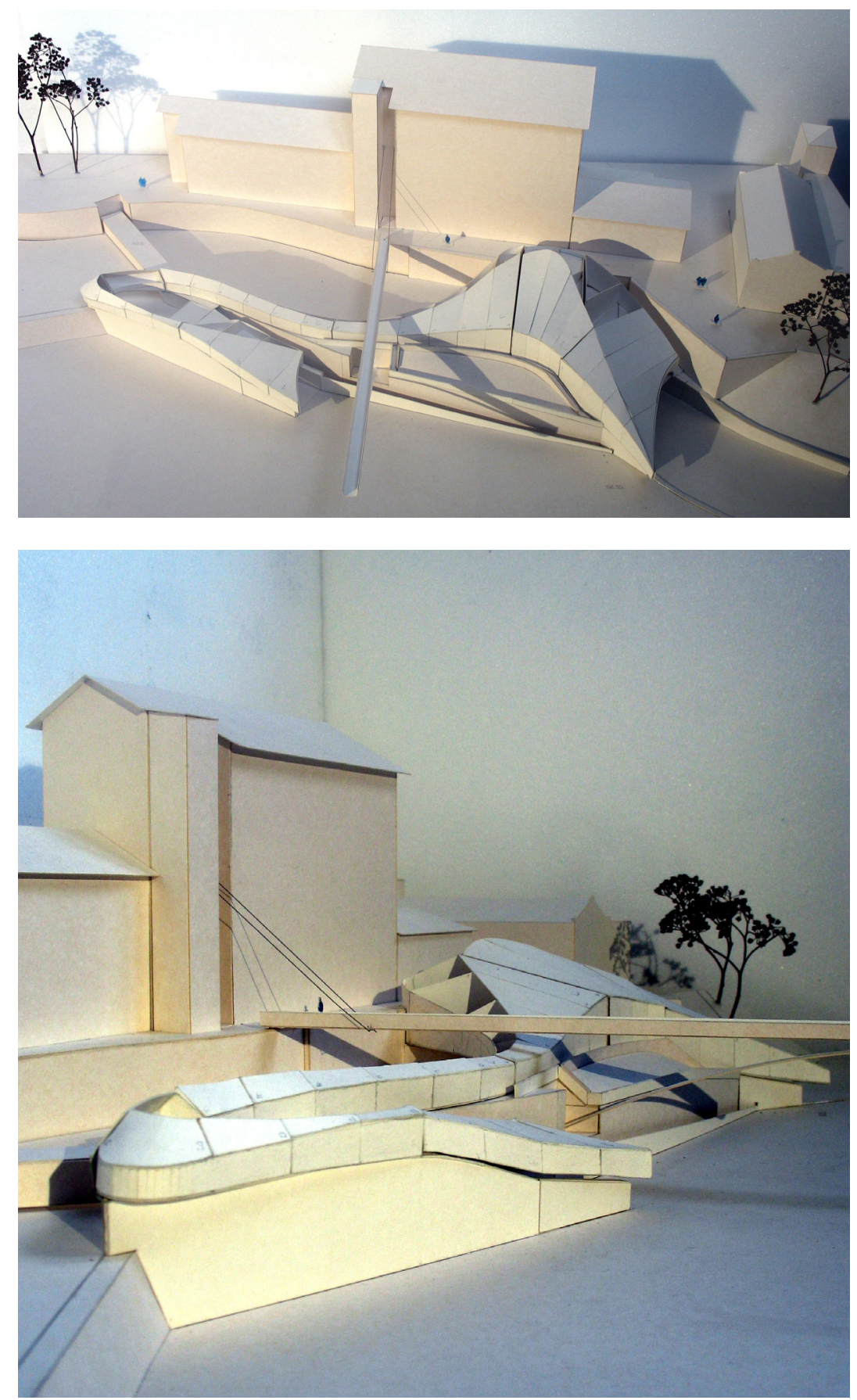

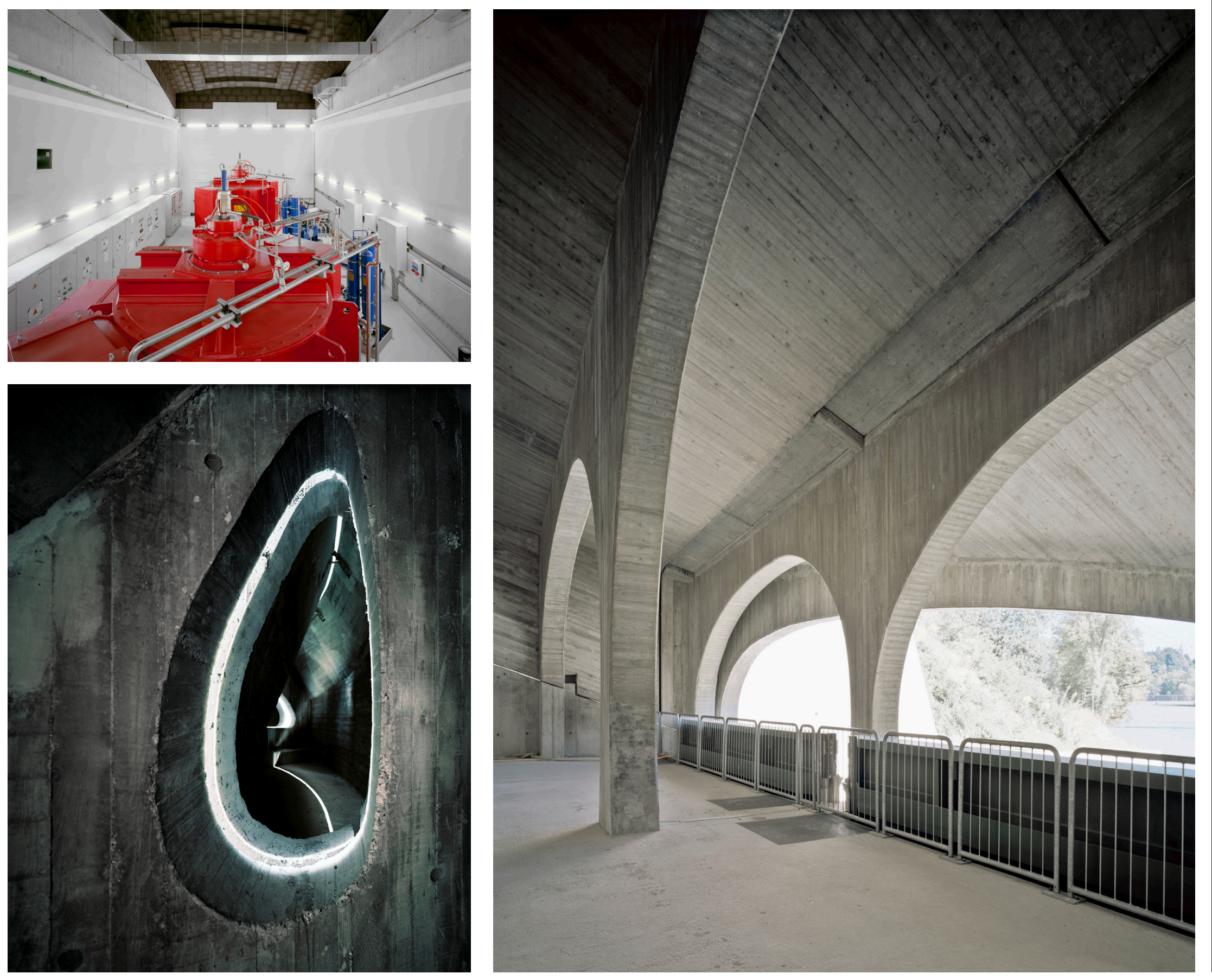


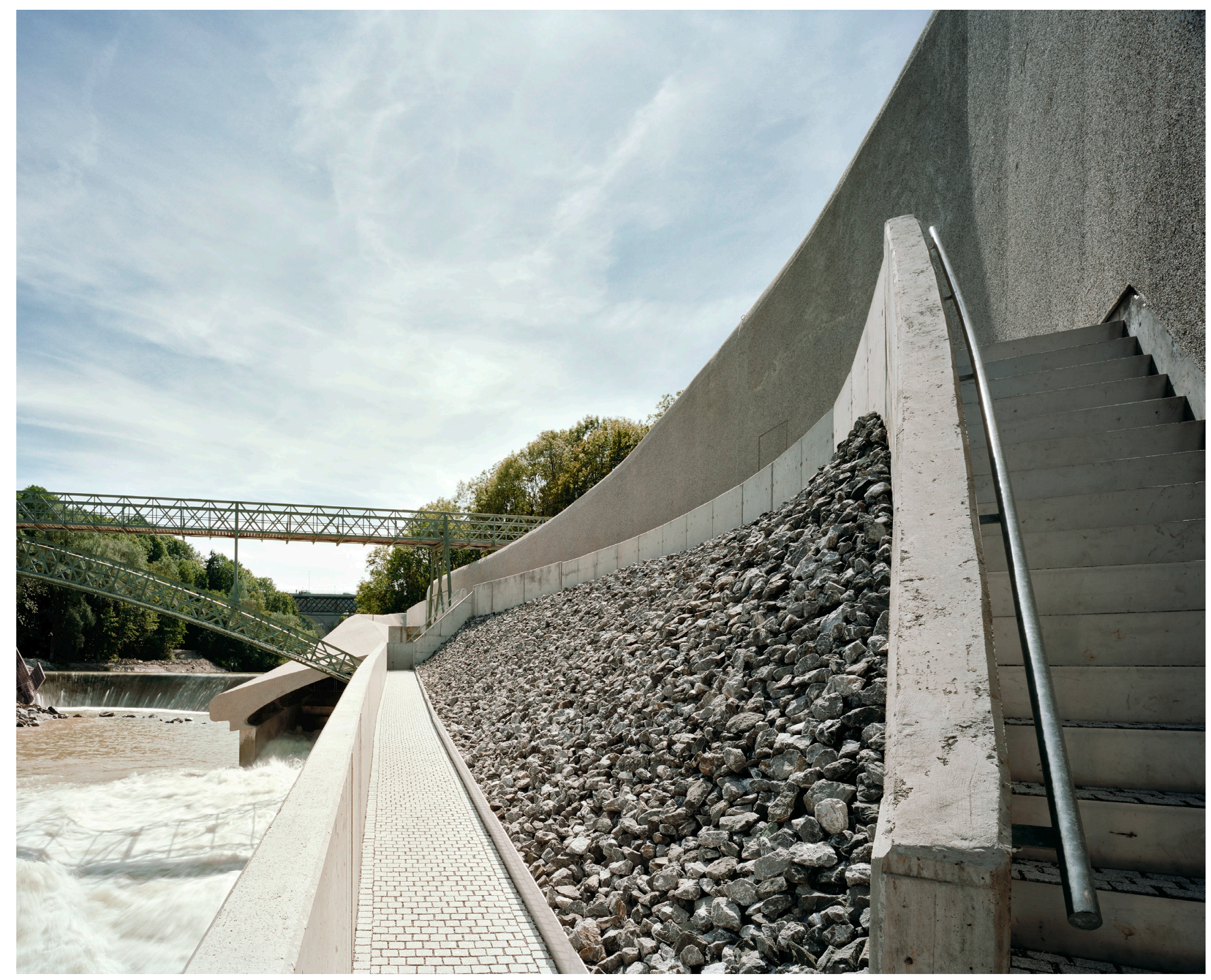

